\title{
Effects of different light quality on growth, photosynthetic characteristic and chloroplast ultrastructure of upland cotton (Gossypium hirsutum L.) seedlings
}

\author{
Hui-min LII,2*, Can-ming Tang ${ }^{1 *}$, Zhi-gang XU1 \\ ${ }^{1}$ College of Agronomy, National Key Laboratory of Crop Genetics \& Germplasm Enhancement, Nanjing Agricultural University, Nanjing, \\ 210095, Jiangsu, P. R. China, ${ }^{2}$ College of Life Science, Anhui Science and Technology University, Fengyang, Anhui, 233100, P. R. China
}

\section{A B S T R A C T}

The objective of the present study was to evaluate the effects of different light emitting diodes (LEDs) on growth, photosynthetic characteristic and chloroplast ultrastructure of upland cotton (Gossypium hirsutum L.) seedlings. Seedlings of the cultivar Sumian 22 were grown under seven different lights including blue (B) plus red (R) LEDs BR (1:8, 1:3, 1:1, 3:1), B LEDs, R LEDs and fluorescent lamps (FL) with the $100 \mu \mathrm{mol} \mathrm{m}{ }^{-2} \mathrm{~s}^{-1}$ photosynthesis photon flux (PPF) and a 12 hour photoperiod for 40 days. Compared with FL, fresh mass, dry mass, root length, stem width, root activity, length of palisade tissue and stomatal frequencies were significantly greater as well as the thickest grana lamella in chloroplast in seedlings grown under BR1:8 LEDs; The chlorophyll a, chlorophyll b, total chlorophyll contents, photosynthetic rate, leaf thickness, spongy tissue length and stomatal areas were highest in seedlings under B LEDs; The stem length, leaf area, sucrose, soluble sugar and starch concentrations were highest as well as the greatest number and volume of starch grains in chloroplast in seedlings under R LEDs. It was suggested that BR1:8 LEDs might be used as a primary light for the cultivation of upland cotton seedlings under controlled conditions.

Keywords: Light emitting diodes; Photosynthetic characteristic; Chloroplast ultrastructure; Spongy tissue length; Stomatal area; Upland cotton

\section{INTRODUCTION}

Light affected the growth and development of plants (Gong et al., 2015). Two main light qualities were detected by pigment systems in plants, phytochrome and blueabsorbing pigments (BAPs). Phytochrome was most sensitive to red light and far-red light, while BAPs are influenced by $\mathrm{B}$ and ultraviolet-A (UV-A) light spectrum (Moe and Heins, 1990). Both light quantity of photon flux and wavelength were very important for plant growth and development (Moshe and Dalia, 2007). R LEDs light might increase starch accumulation by inhibiting the translocation of photosynthates out of leaves (Saebo et al., 1995). In addition, B LEDs light were important for the formation of chlorophyll, chloroplast development and stomatal opening (Senger et al., 1982). Light from B plus R LEDs influenced anatomical features, photosynthesis, growth and development in pepper, lily, strawberry, cherry tomato, rapeseed, non-heading Chinese cabbage and chrysanthemum (Schuerger et al., 1997; Lian et al., 2002; Nhut et al., 2003; Kim et al., 2004; Kurilcik et al., 2008; Liu et al., 2011a, 2011b; Fan et al., 2013a; 2013b; Li et al., 2013).

LEDs were solid-state, long-lasting and durable sources of narrow-band light which can be used in a range of horticultural and photo-biological applications. LEDs provided an opportunity to optimize the spectra for a given plant response and have been used as primary light

\footnotetext{
*Corresponding author:

Hui-min LI, College of Agronomy, National Key Laboratory of Crop Genetics \& Germplasm Enhancement, Nanjing Agricultural University, Nanjing, 210095, Jiangsu, P. R. China, College of Life Science, Anhui Science and Technology University, Fengyang, Anhui, 233100, P. R. China. E-mail: hmli0621@163.com;

Author's current work unit:

Can-ming TANG, College of Agronomy, National Key Laboratory of Crop Genetics \& Germplasm Enhancement, Nanjing Agricultural University, Nanjing, 210095, Jiangsu, P. R. China. E-mail: tangcm@njau.edu.cn.
}

Received: 10 October 2016; Revised: 19 January 2017; Accepted: 21 January 2017; Published Online: 29 January 2017 
sources for space-based plant research chambers and bio-regenerative life-support systems, such as plant tissue culture, establishment horticulture, seedling production and zoological experiments (Guo et al., 2008; Stutte, 2009). LEDs had been successfully used to cultivate several plant species, including lettuce (Kim et al., 2004; Kim et al., 2006; Li and Kubota, 2009; Stutte et al., 2009), pepper (Schuerger et al., 1997), spinach (Yorio et al., 2001), Chinese cabbage (Avercheva et al., 2009), non-heading Chinese cabbage (Li et al., 2012; Fan et al., 2013b), cucumber (Sander et al., 2010), potato (Jao and Fang, 2004), tomato (Liu et al., 2011a; 2011b; Fan et al., 2013a), upland cotton (Li et al., 2010), maize (Felker et al., 1995), wheat (Goins et al., 1997), strawberry (Nhut et al., 2003), grape (Poudel et al., 2008), cymbidium (Tanaka et al., 1998), lilium (Lian et al., 2002), marigold and salvia (Heo et al., 2002), chrysanthemum (Kim et al., 2004; Lund et al., 2007; Kurilcik et al., 2008) and rehmanniae (Hahn et al., 2000).

Although the previous studies had identified various physiological and morphological effects of light quality on many plant species, few reports had addressed the effects of LEDs and FL on growth, photosynthesis and chloroplast ultrastructure of upland cotton seedlings. Plant leaves were the main organ of photosynthesis, and structure and function of chloroplasts are important for the growth of plants and influence physiological and ecological responses (Peng and Zhou, 2009). Upland cotton was the primary species of cotton cultivated for fibers to be used in textile industry (Kouakou et al., 2007). Seedling culture and transplantation was major system for Chinese cotton production. The system of cotton seedling culture and transplantation was an important breakthrough for cotton production and cultivation technology, helping to the double yields of seeds and fiber in China. It is necessary to study the most effective lights for the industrial cultivation of upland cotton seedlings. The major objective of the present study was to examine the effects of $\mathrm{BR}(1: 8,1: 3$, 1:1, 3:1) LEDs, B LEDs, R LEDs and FL (control) on growth, photosynthesis and chloroplast ultrastructure of upland cotton seedlings and select a better light source for upland cotton seedlings grown under the controlled conditions. The present study should provide a theoretical basis and technical support for the reasonable selection of light source for new LEDs lights in cotton factory seedling and facility cultivation.

\section{MATERIALS AND METHODS}

\section{Plant materials}

The experiments were conducted in experiment at Nanjing Agricultural University. Upland cotton cultivar, Sumian 22, was used as the plant material. Seeds of similar size were selected for sowing. Seeds were sown in cells filled with vermiculite and peat $(1: 1 \mathrm{v} / \mathrm{v})$ for hydroponic cultivation, with one seed per cell. Culture conditions were maintained at $25^{\circ} \mathrm{C}-26^{\circ} \mathrm{C}$ (day and night) and $40 \%-50 \%$ (relative humidity) in greenhouse. After 7 days, seedlings with two expanded cotyledons were transplanted into plastic tanks $(8 \mathrm{~cm} \times 15 \mathrm{~cm})$ which containing vermiculite and peat $(1: 1 \mathrm{v} / \mathrm{v})$. The seedlings were cultured in incubator $(80 \mathrm{~cm} \times 180 \mathrm{~cm})$ which was designed and made by Nanjing Agricultural University. The illumination system is arranged on the upper part of the incubator, and the light intensity is controlled by adjusting the number of lamp bulbs and the distance between the lamp and the plant canopy. Temperature and humidity can be controlled automatically.

\section{Experimental design}

Seedlings were treated by BR (1:8, 1:3, 1:1, 3:1) LEDs, B LEDs, R LEDs and FL (control). Cultures were maintained at $25^{\circ} \mathrm{C}-26^{\circ} \mathrm{C}$ (day and night) and $40 \%-50 \%$ (relative humidity) with $100 \mu \mathrm{mol} \mathrm{s}^{-1} \mathrm{~m}^{-2}$ photosynthesis photon flux (PPF) for a 12 hour photoperiod. The positions of seedlings were assigned to each light treatment according to the same light intensity; The experiment was completely randomized design with three replications. Seedlings were treated by the type's lights for 40 days. The spectral-energy distribution of the BR $(1: 8,1: 3,1: 1,3: 1,11 \mathrm{~W})$ LEDs, B LEDs (11W), R LEDs (11W), and FL (T5, 28W) was measured using an spectral photometer (OPT-2000, Optpeco Inc., Beijing, China; Fig. 1). The BR LEDs was determined according to the proportion of total light intensity.

\section{Assessment of morphological index}

The plants were harvested 40 days after applying treatment. Seedlings were dried at $85^{\circ} \mathrm{C}$ until a constant mass was reached to determine dry mass. The mass of each seedling was measured using an electronic balance. Stem length was measured from the main stem base to the top of a seedling using a ruler, and stem diameter was measured at the internode nearest to the root using a Venire caliper. The leaf area (in $\mathrm{cm}^{2}$ ) of each seedling was measured using a Leaf Area Meter (LI-3000, LI-COR Inc., USA).

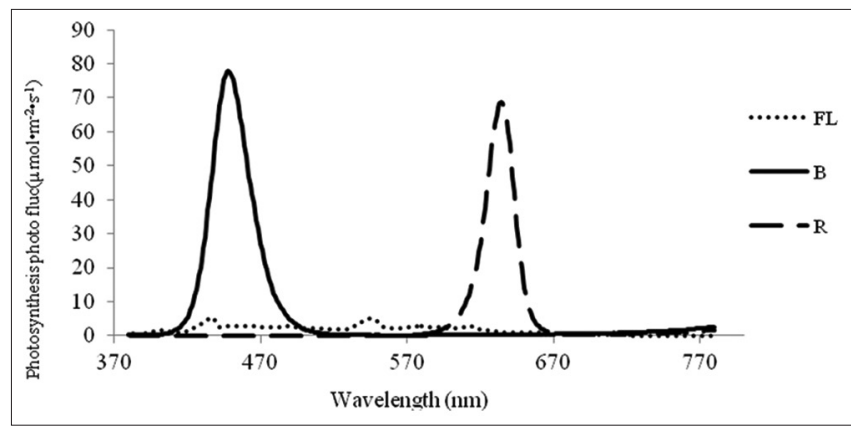

Fig 1. The spectral distribution of light treatments. FL: Fluorescent lamp; B: 100\% blue light; R: 100\% red light. 


\section{Assessment of chlorophyll content}

Chlorophyll was extracted from the leaves of fifteen seedlings at a similar position within each treatment to examine chlorophyll content. The fresh leaves were weighed to $0.1 \mathrm{~g}$. $0.1 \mathrm{~g}$ leaf samples were placed into a mortar with quartz sand, and $10 \mathrm{~mL}$ of $80 \%$ acetone was added. The chlorophyll was then extracted until the leaf turned white. The optical density (OD) was measured using a spectrophotometer (UV-1200, Jin Peng Inc., Shanghai, China) at $663 \mathrm{~nm}$ for chlorophyll a (Chl. a, OD663) and at $645 \mathrm{~nm}$ for chlorophyll b (Chl. b, OD645). The concentrations of chlorophyll $\mathrm{a}$ and chlorophyll $\mathrm{b}$ were determined from the following equations (Lichtenthaler and Wellburn, 1983):

$$
\begin{aligned}
\text { Chlorophyll a }\left(\mathrm{mg}^{\cdot} \mathrm{g}^{-1}\right)= & (12.72 \text { OD663-2.59 OD645 }) \\
& \mathrm{V} / 1000 \mathrm{~W}
\end{aligned}
$$

Chlorophyll b $\left(\mathrm{mg} \cdot \mathrm{g}^{-1}\right)=(22.88$ OD645-4.67 OD663) $\mathrm{V} / 1000 \mathrm{~W}$

Total chlorophyll $\left(\mathrm{mg} \cdot \mathrm{g}^{-1}\right)=(8.05$ OD663 +20.29 OD645 $)$ $\mathrm{V} / 1000 \mathrm{~W}$

Where $\mathrm{V}$ is the total volume of acetone extract $(\mathrm{mL}), \mathrm{W}$ is the fresh weight (g) of the sample, $\mathrm{Ca}$ and $\mathrm{Cb}$ is respectively the concentration of chlorophyll $\mathrm{a}$ and chlorophyll $\mathrm{b}$.

\section{Assessment of leaf photosynthesis}

When plants were grown under different lights for 40 days, measurements were taken on the functional leaves (the third leaves from the top) of the main stems of three seedlings in triplicate. The photosynthetic rate was performed with a portable photosynthesis system (LI-6400, LI-COR Inc., Lincoln, USA) from 9:30-10:30 am. PPF was set to measure at $100 \mu \mathrm{mol} \mathrm{m} \mathrm{m}^{-2} \mathrm{~s}^{-1}$, and the experimental conditions such as leaf temperature, $\mathrm{CO}_{2}$ concentration and relative humidity were $24 \pm 2^{\circ} \mathrm{C}, 380 \pm 5 \mu \mathrm{L} / \mathrm{L}$, and $40 \pm 5 \%$, respectively (Zeng et al., 2012).

\section{Assessment of root activity}

A root sample was excised from the lateral roots of fifteen seedlings at a similar position within each treatment. The $0.5 \mathrm{~g}$ fresh sample was treated in $5 \mathrm{~mL}$ of $0.1 \% 2,3$, 5 -triphenyltetrazolium chloride (TTC) and $5 \mathrm{~mL}$ of 0.067 $\mathrm{M}$ potassium phosphate buffer, mixed thoroughly and kept for two hours at $37^{\circ} \mathrm{C}$. The reaction was terminated with $2 \mathrm{~mL}$ of $1 \mathrm{M} \mathrm{H}_{2} \mathrm{SO}_{4}$. Then the root was removed, rinsed two to three times with distilled water, placed into a mortar with quartz sand and $10 \mathrm{~mL}$ of acetone and ground until it turned white. To make a standard curve, 50, 100, 150, 200 or $250 \mu \mathrm{L}$ of $0.1 \%$ T'TC was added to five volumetric flasks, and $\mathrm{Na}_{2} \mathrm{~S}_{2} \mathrm{O}_{4}$ and distilled water were added to reach a volume of $10 \mathrm{~mL}$. The optical density was measured using a UV-1200 spectrophotometer (UV-1200, Jin Peng Inc., Shanghai, China) at $490 \mathrm{~nm}$. Root activity was determined using the following equation:

Root activity $\left(\mathrm{mg}^{\cdot} \mathrm{g}^{-1} \mathrm{~h}^{-1}\right)=\varrho \mathrm{V} / \mathrm{W} \mathrm{T}$ (Li et al., 2010). Where Q is optical density, $\mathrm{V}$ is volume $(\mathrm{mL})$ of acetone extract, $\mathrm{T}$ is the time $(\mathrm{h})$ of reactions, and $\mathrm{W}$ is fresh mass $(\mathrm{g})$ of the sample.

\section{Assessment of sugar and starch contents}

Total sugar content was extracted using the method of Martin (Martin et al., 2000) with slight modifications. Leaves $(0.5 \mathrm{~g})$ were ground in a mortar with liquid nitrogen. Then $1 \mathrm{~mL}$ of $80 \%$ ethanol was added, and the mixture was filtered through filter paper. The filtrates were recovered, and the residues were washed again with $70 \%$ ethanol and filtered. Both filtrates were mixed, and then $3 \mathrm{~mL}$ of distilled water was added. The extract was centrifuged at 12 , 000r for $15 \mathrm{~min}$, and $1 \mathrm{~mL}$ of supernatant was collected. Soluble sugar was determined by the sulfuric acid-anthrone method and measured at $620 \mathrm{~nm}$. Sucrose was determined by the phloroglucinol method and measured a UV-1200 spectrophotometer (UV-1200, Jin Peng Inc., Shanghai, China) at $480 \mathrm{~nm}$. The method of Takahashi (Takahashi et al., 1995) was used for starch extraction. The residue obtained after ethanol extraction was re-suspended with 0.1 $\mathrm{M}$ sodium acetate buffer ( $\mathrm{pH} 4.8$ ) and boiled for $20 \mathrm{~min}$. The gelatinized starch was digested with amyloglucosidase for four hours at $37^{\circ} \mathrm{C}$ and boiled again to stop the enzymatic reaction. After cooling, the mixture was centrifuged, and the amount of soluble sugar in the supernatant was determined by anthrone colorimetry. The starch content was estimated by converting glucose to starch equivalents using a factor of 0.9 (Li et al., 2010).

\section{Assessment of leaf anatomical features}

Leaf sections $\left(1 \mathrm{~cm}^{2} ; 1 \mathrm{~cm} \times 1 \mathrm{~cm}\right)$ including small lateral veins from fully expanded leaves (from the second or third nodes) of fifteen seedlings were selected and fixed for two days in $50 \mathrm{~mL}$ of formaldehyde-based fixative solution containing 95\% ethanol, glacial acetic acid and $37 \%$ formaldehyde $(95: 5: 5, \mathrm{v} / \mathrm{v} / \mathrm{v})$. The leaf samples were dehydrated in a graded ethanol series $(75 \%, 85 \%, 95 \%$, $100 \%$, and $100 \%$ ), embedded in paraffin, sectioned, mounted on glass slides, and treated with safranin and fast green stain (Li et al., 2010). The stained sections of leaf tissues were analyzed using a microscope (DP71, Olympus Inc., Japan). Images were viewed on a monitor and analyzed using Motic Images Plus 2.0. Leaf cross-sections were measured for leaf thickness, lengths of palisade tissue and spongy tissue.

\section{Assessment of stomatal features}

Samples of fifteen seedlings were collected from fully expanded leaves (from the second or third nodes) of 
each seedling for stomatal observation. Absorbent cotton fiber was wetted with water, and the abaxial and adaxial surfaces of the leaves were swabbed. When the leaf was dry, transparent nail polish was brushed onto both sides. When the nail polish had air dried and formed a membrane, transparent adhesive tape was pressed onto both sides of each leaf, stripped, and then pressed on a slide. The slide was treated with a neutral plastic seal to make a temporary slide. Epidermal fingerprints were observed by using an optical microscope (Li et al., 2010). The slides were analyzed using an Olympus microscope (DP71, Olympus Inc., Japan). The area and frequency of stomata were measured using Motic Images Plus 2.0.

\section{Assessment of chloroplast ultrastructure}

Fully expanded leaves from fifteen seedlings at a similar position within each treatment were destructively sampled. Leaf sections $\left(0.25 \mathrm{~cm}^{2} ; 0.5 \mathrm{~cm} \times 0.5 \mathrm{~cm}\right)$ including small lateral veins were excised from the second leaf from the top and about $1 \mathrm{~cm}$ away from the petiole base. The samples were fixed in $2.5 \%$ glutaraldehyde $(\mathrm{pH} 7.0)$ at $4^{\circ} \mathrm{C}$ for 12 hours and bled by vacuum pump. The leaf sections were rinsed three times with $0.1 \mathrm{M}$ phosphate buffer for $20 \mathrm{~min}$, fixed in 1\% osmic acid ( $\mathrm{pH} 7.0$ ) for two hours, rinsed three times with $0.1 \mathrm{M}$ phosphate buffer for $20 \mathrm{~min}$, and then dehydrated in an ethanol series $(30 \%, 50 \%, 70 \%, 80 \%, 90 \%)$ for $20 \mathrm{~min}$ each. The dehydrated samples were imbued with acetone and embedded in Epon-812 epoxy resin, polymerized, sectioned, and stained with $2 \%$ uranyl acetate solution (pH 4.2) for 30 min followed by lead citrate solution (pH 12) for $30 \mathrm{~min}$. The stained samples were then rinsed with distilled water 30 times. After the sections were dry, the samples were observed using a transmission electron microscope (H-7650, Hitachi Inc., Japan).

\section{Statistical analyses}

Statistical analyses were conducted using SPSS statistical product and service solutions for windows version 18.0 (SPSS, Chicago, USA). Each treatment was replicated three times. The data were analyzed using an analysis of variance (ANOVA), and the differences between means were tested using Duncan's multiple range test $(\mathrm{P}<0.05)$.

\section{RESULTS}

Changes in growth and chlorophyll contents under different blue plus red LEDs lights

The measured parameters of the growth and morphogenesis of seedlings, including fresh weight, dry weight, root length, stem length, stem width and leaf area, showed differences under the four mixtures of blue plus red LEDs. Fresh weight, dry weight, root length, stem length, stem width and leaf area were the greatest in the seedlings grown under the BR1:8 LEDs compared with the other lights (Table 1). The present results demonstrate that the BR1:8 LEDs provided more suitable light for the growth of upland cotton seedlings than the other ratios of blue plus red LEDs (BR1:3, 1:1 or 3:1). The chlorophyll a, chlorophyll $\mathrm{b}$ and total chlorophyll contents were the greatest in the seedlings grown under BR1:8, which showed significantly higher than the BR3:1, 1:1 or 1:3; However, the BR3:1, 1:1 or 1:3 lights had no significant drfferences (Table 2).

\section{Changes in growth parameters under different lights} Different lights had variable effects on the growth of upland cotton seedlings. Compared with FL, fresh mass, dry mass, root length and stem width were significantly greater in seedlings grown under BR1:8 LEDs; Stem length and leaf area were significantly greater in seedlings grown under R LEDs (Table 3).

\section{Changes in root activity under different lights}

Different lights varied significantly in their effects on root activity in upland cotton seedlings. Root activity of seedlings grown under BR1:8 LEDs was $95.26 \mathrm{mg} \cdot \mathrm{g}^{-1} \mathrm{~h}^{-1}$, a value $28.21 \%$ higher than those of the seedlings grown under B LEDs. Root activity was the lowest in seedlings grown under FL (Fig. 2).

\section{Changes in leaf chlorophyll contents under different lights}

The trend of chlorophyll a, chlorophyll b and total chlorophyll contents under four treatments were the same, the values were highest in seedlings under B LEDs, followed by those grown under BR1:8 LEDs, and the lowest in those grown under FL (Fig. 3). However, contents of chlorophyll a, chlorophyll b and total

Table 1: The effects of different blue plus red LEDs lights on the growth of upland cotton seedlings

\begin{tabular}{lcccccc}
\hline $\begin{array}{l}\text { Light } \\
\text { treatment }\end{array}$ & Fresh weight $\mathbf{( g )}$ & Dry weight $\mathbf{( g )}$ & Root length $(\mathbf{c m})$ & Stem length $(\mathbf{c m})$ & Stem width $(\mathbf{c m})$ & Leaf area $(\mathbf{c m})^{2}$ \\
\hline $\mathrm{B}: \mathrm{R}=1: 8$ & $5.46 \pm 0.03 \mathrm{a}$ & $0.72 \pm 0.02 \mathrm{a}$ & $12.40 \pm 0.04 \mathrm{a}$ & $21.35 \pm 0.56 \mathrm{a}$ & $2.33 \pm 0.03 \mathrm{a}$ & $53.70 \pm 0.45 \mathrm{a}$ \\
$\mathrm{B}: \mathrm{R}=1: 3$ & $4.19 \pm 0.06 \mathrm{c}$ & $0.60 \pm 0.03 \mathrm{~b}$ & $11.15 \pm 0.12 \mathrm{~b}$ & $18.60 \pm 0.45 \mathrm{~b}$ & $2.01 \pm 0.06 \mathrm{~b}$ & $40.06 \pm 0.96 \mathrm{~b}$ \\
$\mathrm{~B}: \mathrm{R}=1: 1$ & $4.74 \pm 0.05 \mathrm{~b}$ & $0.62 \pm 0.04 \mathrm{~b}$ & $10.10 \pm 0.09 \mathrm{c}$ & $19.00 \pm 0.52 \mathrm{~b}$ & $1.75 \pm 0.12 \mathrm{c}$ & $41.52 \pm 0.87 \mathrm{~b}$ \\
$\mathrm{~B}: \mathrm{R}=3: 1$ & $4.84 \pm 0.06 \mathrm{~b}$ & $0.61 \pm 0.05 \mathrm{~b}$ & $10.95 \pm 0.08 \mathrm{~b}$ & $18.30 \pm 0.78 \mathrm{~b}$ & $2.04 \pm 0.06 \mathrm{~b}$ & $42.80 \pm 0.56 \mathrm{~b}$ \\
\hline
\end{tabular}

$\mathrm{B}: \mathrm{R}=1: 8,11.1 \%$ blue plus $88.9 \%$ red light-emitting diodes; $\mathrm{B}: \mathrm{R}=1: 3,25 \%$ blue plus $75 \%$ red light-emitting diodes; $\mathrm{B}: \mathrm{R}=1: 1,50 \%$ Blue plus $50 \%$ red light-emitting diodes; $B: R=3: 1,75 \%$ Blue plus $25 \%$ red light-emitting diodes; Values are the mean \pm standard deviation; The different letters within the columns indicate significant differences at $\mathrm{P}<0.05$ by Duncan's Multiple Range Test 


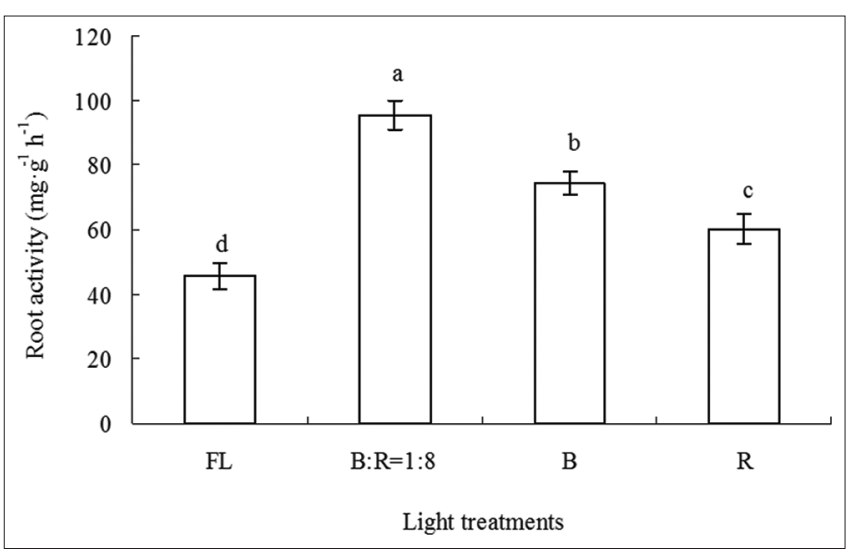

Fig 2. Effects of different lights on root activity of upland cotton seedlings. FL, fluorescent lamps; $B$ : $R=1: 8$, Blue plus red light emitting diodes; $B$, Blue light emitting diodes; R, Red light emitting diodes; The different letters indicate significant differences at $\mathrm{P}<0.05$ by Duncan's Test.

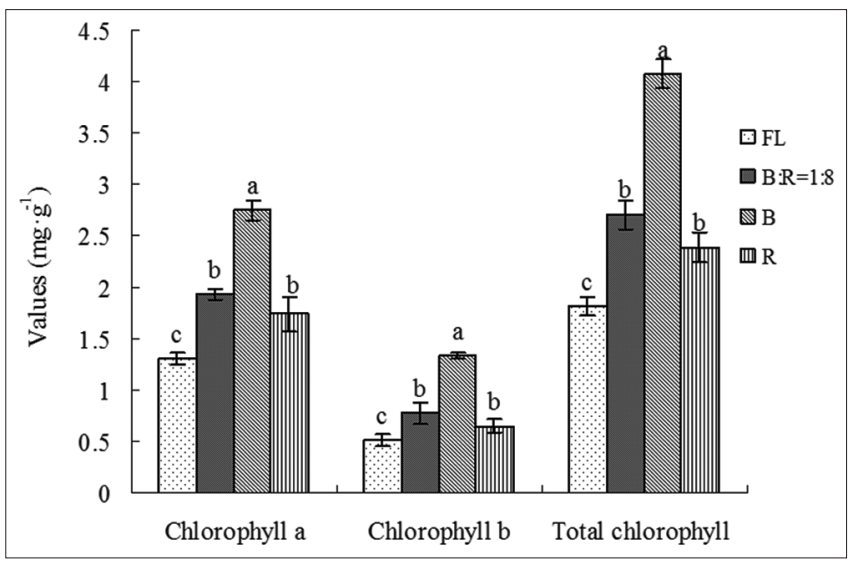

Fig 3. Effects of different lights on chlorophyll content of upland cotton seedlings. FL, fluorescent lamps; $B: R=1: 8$, Blue plus red light emitting diodes; B, Blue light emitting diodes; R, Red light emitting diodes; The different letters indicate significant differences at $P<0.05$ by Duncan's Test.

Table 2: The effects of different blue plus red LEDs lights on the chlorophyll contents of upland cotton seedlings

\begin{tabular}{lccc}
$\begin{array}{l}\text { Light } \\
\text { treatment }\end{array}$ & $\begin{array}{c}\text { Chl. a } \\
\left(\mathbf{m g} \cdot \mathbf{g}^{-1}\right)\end{array}$ & $\begin{array}{c}\text { Chl. b } \\
\left(\mathbf{m g} \cdot \mathbf{g}^{-1}\right)\end{array}$ & $\begin{array}{c}\text { Chl. }(\mathbf{a}+\mathbf{b}) \\
\left(\mathbf{m g} \cdot \mathbf{g}^{-1}\right)\end{array}$ \\
\hline $\mathrm{B}: \mathrm{R}=1: 8$ & $1.63 \pm 0.02 \mathrm{a}$ & $0.79 \pm 0.03 \mathrm{a}$ & $2.41 \pm 0.03 \mathrm{a}$ \\
$\mathrm{B}: \mathrm{R}=1: 3$ & $1.55 \pm 0.03 \mathrm{~b}$ & $0.67 \pm 0.02 \mathrm{~b}$ & $2.22 \pm 0.05 \mathrm{~b}$ \\
$\mathrm{~B}: \mathrm{R}=1: 1$ & $1.59 \pm 0.01 \mathrm{~b}$ & $0.72 \pm 0.03 \mathrm{~b}$ & $2.28 \pm 0.06 \mathrm{~b}$ \\
$\mathrm{~B}: \mathrm{R}=3: 1$ & $1.58 \pm 0.02 \mathrm{~b}$ & $0.70 \pm 0.02 \mathrm{~b}$ & $2.33 \pm 0.02 \mathrm{~b}$ \\
\hline
\end{tabular}

$B: R=1: 8,11.1 \%$ Blue plus $88.9 \%$ red light-emitting diodes, $B: R=1: 3,25 \%$ Blue plus $75 \%$ red light-emitting diodes, $B: R=1: 1,50 \%$ Blue plus $50 \%$ red light-emitting diodes; $B: R=3: 1,75 \%$ Blue plus $25 \%$ red light-emitting diodes; Values are the mean \pm standard deviation; The different letters within the columns indicate significant differences at $\mathrm{P}<0.05$ by Duncan's Multiple Range Test chlorophyll of seedlings under BR1:8 LEDs and R LEDs were not statistically different.

Changes in photosynthetic rate under different lights Different lights exhibited obvious differences in their effects on photosynthetic rate of upland cotton seedlings. Photosynthetic rate of seedlings grown under BR1:8 LEDs was $8.19 \mu \mathrm{mol} \mathrm{m}^{-2} \mathrm{~s}^{-1}$, a value $44.9 \%$ higher than those of the seedlings grown under FL. Compared with FL, photosynthetic rate of seedlings grown under B LEDs were the greatest. However, photosynthetic rate of seedlings grown under BR1:8 LEDs and B LEDs were not statistically different (Fig. 4).

\section{Changes in photosynthetic production under different lights}

The trend of sucrose, soluble sugar and starch concentrations under four treatments were the same, the values were highest in seedlings under R LEDs, followed by BR1:8 LEDs and the lowest in those grown under FL (Table 4).

\section{Changes in leaf anatomy under different lights}

Leaf thickness and spongy tissue length were the greatest in seedlings grown under B LEDs, followed by those grown under BR1:8 LEDs, and the smallest in seedlings grown under FL. Leaf thickness of seedlings under R LEDs and FL were not statistically different. Length of palisade tissue was the greatest in seedlings grown under BR1:8 LEDs. However, leaf thickness of seedlings under B and R LEDs were not statistically different (Table 5).

\section{Changes in chloroplast ultrastructure under different lights}

Seedlings grown under BR1:8 LEDs exhibited a high integrity of the chloroplast ultrastructure with welldeveloped lamellar structure, elliptical and well-developed starch grains, and thick grana and lamellae (Fig. 5b and 6b). Seedlings grown under B LEDs also exhibited a high integrity of the chloroplast ultrastructure with a clearly visible lamellar structure and elliptical starch grains (Fig. 5c and 6c). When seedlings grown under R LEDs, the most chloroplasts exhibited a disrupted ultrastructure with disjoint and ruptured grana and lamellae, but the number and volume of starch grains were greater than in chloroplasts of seedlings grown under the other light sources (Fig. 5d and 6d). When seedlings were grown

Table 3: The effects of different lights on growth of upland cotton seedlings

\begin{tabular}{|c|c|c|c|c|c|c|}
\hline $\begin{array}{l}\text { Light } \\
\text { treatment }\end{array}$ & Fresh mass $(\mathrm{g})$ & Dry mass (g) & Root length (cm) & Stem length (cm) & Stem width $(\mathrm{cm})$ & Leaf area $\left(\mathrm{cm}^{2}\right)$ \\
\hline $\mathrm{FL}$ & $1.79 \pm 0.12 d$ & $0.27 \pm 0.01 c$ & $4.86 \pm 0.23 c$ & $12.50 \pm 0.62 c$ & $1.67 \pm 0.15 c$ & $28.11 \pm 3.27 d$ \\
\hline$B: R=1: 8$ & $3.89 \pm 0.15 a$ & $0.53 \pm 0.03 a$ & $8.06 \pm 0.18 a$ & $17.1 \pm 1.12 a b$ & $2.31 \pm 0.16 a$ & $49.27 \pm 2.24 b$ \\
\hline B & $2.67 \pm 0.18 \mathrm{c}$ & $0.35 \pm 0.04 b$ & $6.44 \pm 0.32 b$ & $15.2 \pm 1.50 b$ & $2.12 \pm 0.14 a b$ & $32.29 \pm 1.45 c$ \\
\hline $\mathrm{R}$ & $3.40 \pm 0.08 b$ & $0.40 \pm 0.02 b$ & $4.94 \pm 0.27 c$ & $18.32 \pm 1.11 \mathrm{a}$ & $1.92 \pm 0.18 b c$ & $63.56 \pm 4.31 a$ \\
\hline
\end{tabular}

FL: Fluorescent lamps, B:R=1:8, Blue plus red light emitting diodes; B: Blue light emitting diodes, R: Red light emitting diodes, Data represent mean \pm standard deviation of three replicates $(n=3)$; The different letters within the columns indicate significant differences at $P<0.05$ by Duncan's Test 
under FL, the chloroplast ultrastructure was substantially modified, the chloroplast lamellae were distorted, and the lamellar structure was faint (Fig. 5a and Fig. 6a). The present results demonstrated that chloroplast structures were well developed in seedlings grown under BR1:8 LEDs and B LEDs.

Changes in leaf stomata features under different lights Stomatal areas on the adaxial and abaxial surfaces of leaves were the greatest in seedlings grown under B LEDs, followed by those grown under BR1:8 LEDs, and the smallest in seedlings grown under FL (Table 6 and Fig. 7). Stomatal frequencies on the adaxial and abaxial surfaces of leaves were the greatest in seedlings grown under BR1:8 LEDs. Stomatal frequencies on the abaxial surfaces of leaves were twice as high as those on the adaxial surfaces in seedlings grown under all light sources, but the stomatal area did not differ significantly between the adaxial and abaxial surfaces.

\section{DISCUSSION}

\section{Blue plus red LEDs provide a better light for plant growth}

The spectrum of sunlight ranges from 380 to $2600 \mathrm{~nm}$. Wavelengths from 390 to $760 \mathrm{~nm}$ (visible light), the physiologically effective wavelengths in sunlight, were known as photo-synthetically available radiation. Blueviolet light (430 to $450 \mathrm{~nm}$ ) and red light (from 640 to $660 \mathrm{~nm}$ ) had the highest effective photosynthetic rates (Pan et al., 2008). The light sources generally used for plant

Table 4: The effects of different lights on photosynthetic products of upland cotton seedlings

\begin{tabular}{lccc}
\hline $\begin{array}{l}\text { Light } \\
\text { treatment }\end{array}$ & $\begin{array}{c}\text { Sucrose } \\
\left(\mathbf{m g} \cdot \mathbf{g}^{-1}\right)\end{array}$ & $\begin{array}{c}\text { Soluble sugar } \\
\left(\mathbf{m g} \cdot \mathbf{~ g}^{-1}\right)\end{array}$ & $\begin{array}{c}\text { Starch } \\
\left(\mathbf{m g} \cdot \mathbf{~ g}^{-1}\right)\end{array}$ \\
\hline FL & $10.93 \pm 0.14 \mathrm{~d}$ & $48.01 \pm 5.32 \mathrm{~d}$ & $6.17 \pm 0.87 \mathrm{~d}$ \\
$\mathrm{~B}: \mathrm{R}=1: 8$ & $16.92 \pm 0.20 \mathrm{~b}$ & $96.30 \pm 8.90 \mathrm{~b}$ & $18.45 \pm 1.28 \mathrm{~b}$ \\
$\mathrm{~B}$ & $15.37 \pm 0.16 \mathrm{c}$ & $66.61 \pm 3.08 \mathrm{c}$ & $10.40 \pm 0.38 \mathrm{c}$ \\
$\mathrm{R}$ & $18.72 \pm 0.60 \mathrm{a}$ & $139.06 \pm 10.56 \mathrm{a}$ & $25.01 \pm 2.07 \mathrm{a}$ \\
\hline
\end{tabular}

FL: Fluorescent lamps, B:R=1:8, Blue plus red light emitting diodes, B: Blue light emitting diodes, $\mathrm{R}$, Red light emitting diodes; Data represent mean \pm standard deviation of three replicates $(n=3)$, The different letters within the columns indicate significant differences at $\mathrm{P}<0.05$ by Duncan's Test

Table 5: The effects of different lights on leaf anatomy of upland cotton seedlings

\begin{tabular}{lccc}
\hline $\begin{array}{l}\text { Light } \\
\text { treatment }\end{array}$ & $\begin{array}{c}\text { Leaf thickness } \\
(\mu \mathrm{m})\end{array}$ & $\begin{array}{c}\text { Palisade tissue } \\
\text { Length }(\mu \mathrm{m})\end{array}$ & $\begin{array}{c}\text { Spongy tissue } \\
\text { Length }(\mu \mathrm{m})\end{array}$ \\
\hline $\mathrm{FL}$ & $189.68 \pm 8.62 \mathrm{c}$ & $54.56 \pm 3.35 \mathrm{c}$ & $80.41 \pm 2.92 \mathrm{~d}$ \\
$\mathrm{~B}: \mathrm{R}=1: 8$ & $250.89 \pm 12.32 \mathrm{~b}$ & $89.90 \pm 1.53 \mathrm{a}$ & $100.56 \pm 2.30 \mathrm{~b}$ \\
$\mathrm{~B}$ & $280.26 \pm 10.02 \mathrm{a}$ & $80.40 \pm 3.36 \mathrm{~b}$ & $120.17 \pm 2.53 \mathrm{a}$ \\
$\mathrm{R}$ & $194.44 \pm 9.12 \mathrm{c}$ & $75.06 \pm 3.39 \mathrm{~b}$ & $86.11 \pm 2.13 \mathrm{c}$ \\
\hline
\end{tabular}

FL: Fluorescent lamps, $B: R=1: 8$, Blue plus red light emitting diodes, $B$ : Blue light emitting diodes, R: Red light emitting diodes; Data represent mean \pm standard deviation of three replicates $(n=3)$; The different letters within the columns indicate significant differences at $\mathrm{P}<0.05$ by Duncan's Test growth under controlled conditions include fluorescent lamps, metal halides, high-pressure sodium lamps, and incandescent lamps (Hahn et al., 2000). The shortcomings of these lights included high energy consumption and low effectiveness toward plant seedlings. Several plants grew well under different blue plus red LEDs lights, including non-heading Chinese Cabbage of B: R (1:8,1:6), Lilium and chrysanthemum of $\mathrm{B}: \mathrm{R}(1: 1)$, strawberry of $\mathrm{B}: \mathrm{R}(3: 7)$ and rapeseed of B: R (3:1) (Hahn et al., 2000; Lian et al., 2002; Nhut et al., 2003; Kim et al., 2004; Li et al., 2012; Fan et al., 2013b; Li et al., 2013). A certain mixture of blue plus red

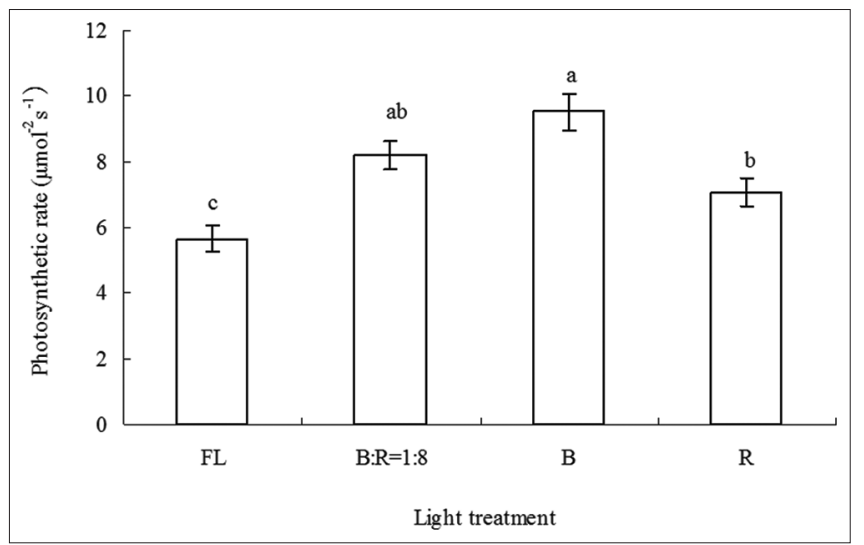

Fig 4. Effects of different lights on the photosynthetic rates of upland cotton seedlings. $F L$, fluorescent lamps; $B: R=1: 8$, Blue plus red light emitting diodes; B, Blue light emitting diodes; R, Red light emitting diodes; The different letters indicate significant differences at $\mathrm{P}<0.05$ by Duncan's Test.

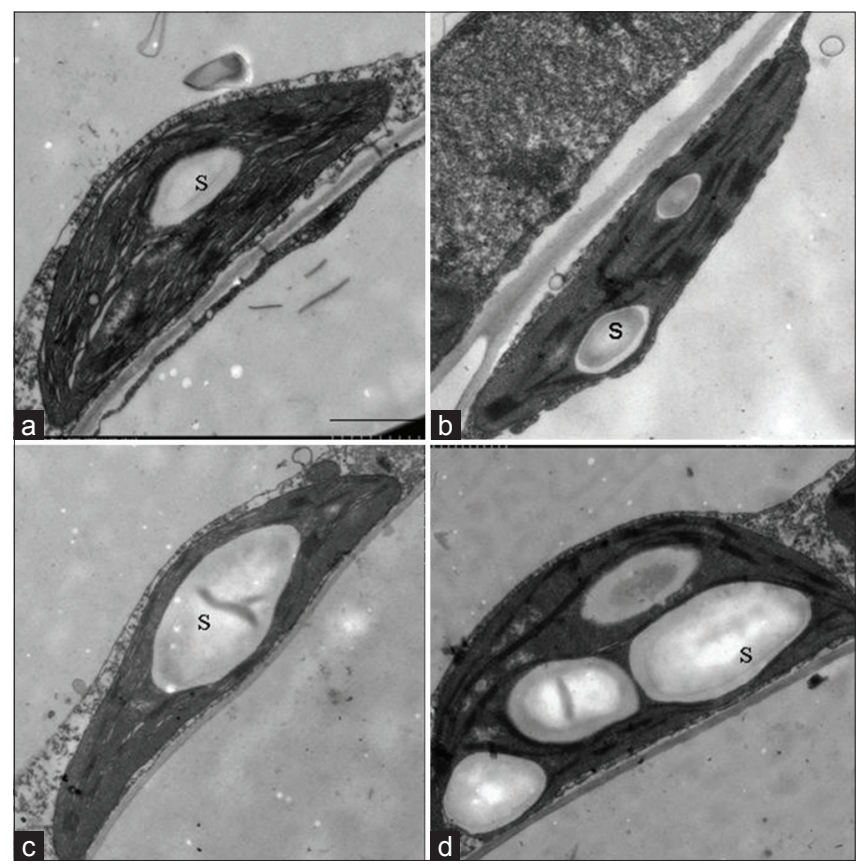

Fig 5. Effects of different lights on starch grains in chloroplast of upland cotton seedlings. (a) Fluorescent lamps; (b) blue plus red light emitting diodes ( $\mathrm{B}: \mathrm{R}=1: 8)$; (c) blue light emitting diodes; (d) red light emitting diodes. S: Starch gains; Bar $=10 \mu \mathrm{m}$. 
LEDs might combine the advantages of monochromic red LEDs and monochromic blue LEDs and overcome

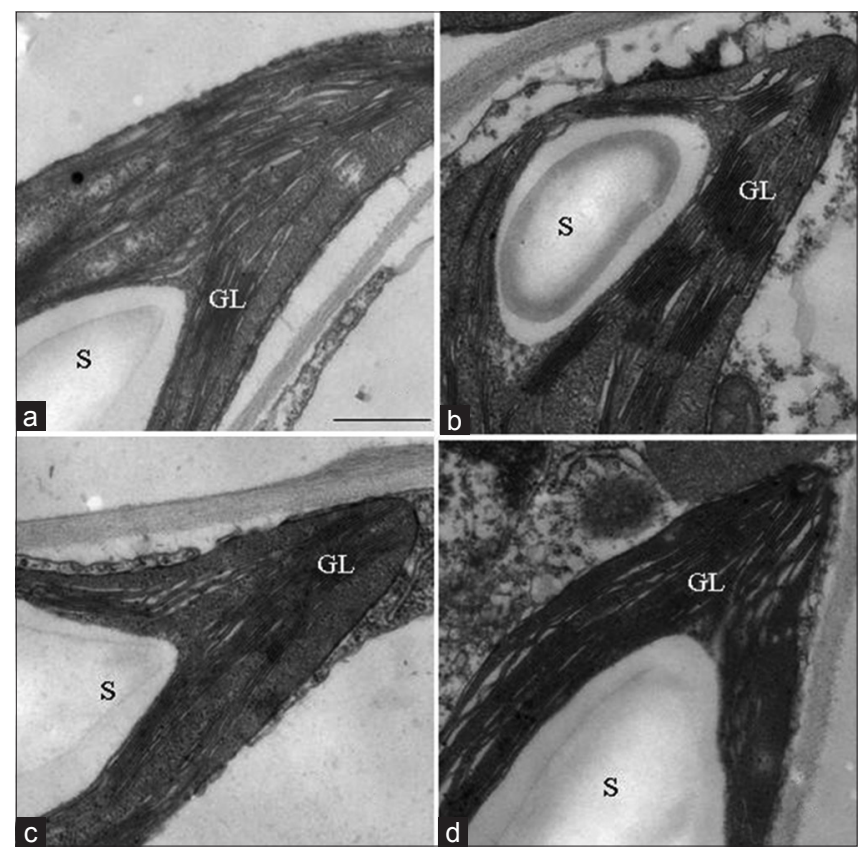

Fig 6. Effects of different lights on the lamella in chloroplasts of upland cotton seedlings. (a) Fluorescent lamps; (b) blue plus red light emitting diodes ( $B: R=1: 8)$; (c) blue light emitting diodes; (d) red light emitting diodes. S: Starch gains; GL: Grana lamellae; Bar $=5 \mu \mathrm{m}$.

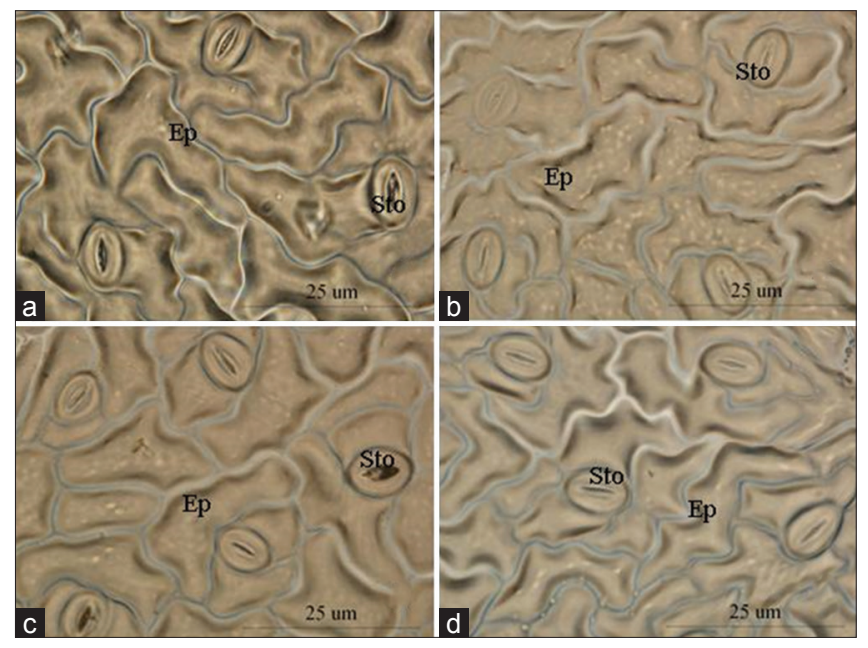

Fig 7. Effects of different lights on the abaxial surface stomata of leaves in upland cotton seedlings. (A) Fluorescent lamps; (B) blue plus red light emitting diodes ( $\mathrm{B}: \mathrm{R}=1: 8)$; (c) blue light emitting diodes; (d) red light emitting diodes. S: Stomata; Ep: Epidermis; Bar $=25 \mu \mathrm{m}$. their disadvantages. The optimal proportion of blue plus red LEDs light varied with the plant species or cultivars. Therefore, identifying the optimal proportion of blue plus red LEDs was critical for promoting the seedlings growth of different plant species. However, few previous papers had examined effects of LEDs, sunlight and fluorescent lamps on growth of upland cotton seedlings. The present results demonstrated that $B: R=1: 8$ LEDs had the significant advantages over sunlight and fluorescent lamps for growth of upland cotton seedlings (Table 1 and 3), so BR1:8 LEDs could be used as a light source for the industrial cultivation of upland cotton seedlings under controlled conditions.

\section{How lights affect leaf structure and its function?}

Plants were able to respond to changes in irradiance environment by modifying structural and physiological traits of their leaves (Wyka et al., 2008; Dunbar-Co et al., 2009; Guan et al., 2011). The structure and function of chloroplasts were important for the growth of plants and influence their physiological responses (Peng and Zhou, 2009). In addition, chloroplast development depended on light, and different wavelengths of light affected chloroplast structure and chemical changes in plants (Deng, 2007). Chloroplasts developed normally under blue plus red light in tomato leaves, and lamella structure was stacked densely (Zhang et al., 2010). Chloroplasts seemed to show the best development under blue, blue plus red, and blue, red plus green light treatments (Liu et al., 2011b). Our results showed that seedlings grown under $\mathrm{B}: \mathrm{R}=1: 8 \mathrm{LEDs}$ exhibited a high integrity of the chloroplast ultrastructure with well-developed lamellar structure and thick grana and lamellae (Fig. 5 B and 6 B), seedlings grown under B LEDs also exhibited a high integrity of the chloroplast ultrastructure with a clearly visible lamellar structure (Fig. 5 C and 6 C). Christopher and Mullet (1994) reported that the expression of a number of chloroplast-encoded genes requires high irradiance B light. Our result was consistent with the previous studies. It might because that cryptochromes (CRYs) and phototropins were specifically sensitive to B light, and phytochromes were specifically sensitive to R light (Whitelam and Halliday, 2007).

The effects of spectral quality on anatomical changes in leaf tissues of pepper plants were generally correlated with

Table 6: The effects of different lights on leaf stomata of upland cotton seedlings

\begin{tabular}{lccccc}
\hline \multirow{2}{*}{$\begin{array}{l}\text { tight } \\
\text { treatment }\end{array}$} & \multicolumn{2}{c}{ Area of a stomata $\left(\mu \mathrm{m}^{2}\right)$} & & \multicolumn{2}{c}{ Stomata frequency $\left(\mathbf{n u m b e r} / \mathrm{mm}^{2}\right)$} \\
\cline { 2 - 4 } & Adaxial surface & Abaxial surface & & Adaxial surface & Abaxial surface \\
\hline $\mathrm{FL}$ & $5.75 \pm 0.12 \mathrm{~d}$ & $5.95 \pm 0.09 \mathrm{~d}$ & & $330.18 \pm 12.62 \mathrm{bc}$ & $1006.70 \pm 22.34 \mathrm{~b}$ \\
$\mathrm{~B}: \mathrm{R}=1: 8$ & $8.04 \pm 0.17 \mathrm{~b}$ & $8.05 \pm 0.21 \mathrm{~b}$ & & $402.60 \pm 12.08 \mathrm{a}$ & $1191.70 \pm 22.42 \mathrm{a}$ \\
$\mathrm{B}$ & $8.75 \pm 0.19 \mathrm{a}$ & $8.85 \pm 0.12 \mathrm{a}$ & & $350.58 \pm 21.35 \mathrm{~b}$ & $1049.40 \pm 32.54 \mathrm{~b}$ \\
$\mathrm{R}$ & $6.05 \pm 0.22 \mathrm{c}$ & $6.66 \pm 0.16 \mathrm{c}$ & & $315.26 \pm 10.12 \mathrm{c}$ & $955.13 \pm 32.36 \mathrm{c}$ \\
\hline
\end{tabular}

FL: Fluorescent lamps, B:R=1:8, Blue plus red light emitting diodes, B: Blue light emitting diodes, R: Red light emitting diodes, Data represent mean \pm standard deviation of three replicates $(n=3)$; The different letters within the columns indicate significant differences at $\mathrm{P}<0.05$ by Duncan's Test 
the amount of B LEDs light (Schuerger et al., 1997). The largest areas of palisade cells had been observed in birch leaves exposed to B LEDs light (Saebo et al., 1995). Palisade tissue cells in tomato leaves under R plus B LEDs were especially well-developed and spongy tissue cells under the same treatment were localized in an orderly fashion (Liu et al., 2011b). The present results demonstrated that leaf thickness and length of spongy tissue were greatest under B LEDs and that the length of palisade tissue was greatest under $\mathrm{B}$ : $\mathrm{R}=1: 8 \mathrm{LEDs}$. The present results are inconsistent with those of Schuerger (1997) and Saebo (1995). The palisade tissues contained more chloroplasts than spongy tissues, and many photosynthetic pigments and enzymes were distributed in the grana and lamella of chloroplasts (Pan et al., 2008). Our results also showed that the seedlings grown under the B plus R light and B light were grown well. Longer palisade tissues and thicker grana lamella of the chloroplast in leaves might be beneficial for the growth of upland cotton seedlings.

Phytochrome affected photosynthesis by affecting chlorophyll content (Casal, 2000). Our results showed that the photosynthetic rate and the pigments was the highest under B LEDs, followed by B: R=1:8 LEDs (Fig. 3 and 4). Meanwhile, the net photosynthetic rate of chrysanthemum was the lowest under B LEDs, but with the highest pigments (Kim et al., 2004). However, the highest photosynthetic pigments were in tomato leaves with R, B plus green LEDs treatment, but net photosynthesis was increased significantly under the R plus B LEDs and R, B plus green LEDs (Liu et al., 2011a; 2011b). Our results were inconsistent with the study of Liu (2011) and Kim (2004). The capacity of leaves photosynthesis was related to the numbers of grana and the dense lamella structure by the different light quality (Liu et al., 2011b). Our result showed that the alteration of the leaf structure seems to relate with the photosynthesis. Stomata had dramatic effected on photosynthesis (Pan et al., 2008). The present results demonstrated that stomatal area of the seedlings grown under B LEDs was greater than that of the seedlings grown under the other light sources (Table 6 and Fig. 7). A direct effect of photochrome on stomatal development and higher SPAD values along with higher numbers of stomata have been recorded under B LEDs (Farquhar and Sharkey, 1982). In the present study, stomatal development might be affected by the chlorophyll content, which is related to the stomatal area in upland cotton seedlings grown under B LEDs.

\section{How LEDs on photosynthetic production metabolism?} Light decreased the chlorophyll content of cymbidium (Tanaka et al., 1998). The lowest pigments in tomato leaves of seedlings were found in those with R LEDs treatment (Liu et al., 2011a). The present results demonstrated that the chlorophyll content was lower (Fig. 3) in upland cotton seedlings grown under R LEDs than those grown under B LEDs or B plus R LEDs. The results are consistent with those of Tanaka and Liu. Therefore, R LEDs may decrease the chlorophyll content of leaves in upland cotton.

Starch was the major storage carbohydrate in plants and has many important functions (Geiger et al., 1995). R LEDs light enhanced starch accumulation in Glycine and Sorghum (Britz and Sager, 1990). Light quality regulated the carbohydrate metabolism of higher plants, the carbohydrate content was high under R LEDs light (Kowallik, 1982). The accumulation of starch in chloroplasts, which was enhanced by R LEDs light, may inhibit photosynthesis. Thus, R LEDs light appeared to inhibit the translocation process (Saebo et al., 1995). Excess starch accumulation inhibited photosynthesis in leaves (Bondada and Syvertsen, 2005). Chloroplast of cherry tomato leaves under R LEDs was relatively rich in starch granules (Liu et al., 2011b). The present results demonstrated that contents of sucrose, soluble sugar and starch were greatest (Table 4) in seedlings grown under R LEDs and that the number and volume of starch grains were significantly increased in chloroplasts of seedlings grown under R LEDs (Fig. $6 \mathrm{~d}$ ), the photosynthetic rate was lower in seedlings grown under R LEDs compared with those grown under blue LEDs or B plus R LEDs (Fig. 4).The present results were consistent with those of the previous studies (Kowallik, 1982; Britz and Sager, 1990; Saebo et al., 1995; Bondada and Syvertsen, 2005; Liu et al., 2011b). The photosynthetic carbon metabolic pathway was not static but was influenced by environmental conditions (Zhang et al., 2015). R LEDs promoted the production of photosynthetic products but might inhibit the transportation of photosynthetic products out of the leaves, starch accumulation in the leaves and leaf photosynthesis was prohibited in upland cotton seedlings.

\section{CONCLUSIONS}

The present study might be the first paper of determining different light qualities on growth, photosynthetic characteristic and chloroplast ultra-structure of upland cotton cultivar Sumian 22. The present results exhibited that $\mathrm{B}: \mathrm{R}=1: 8 \mathrm{LEDs}$ increased the fresh mass, dry mass, root length, stem width, root activity, length of palisade tissue, stomatal frequencies and grana lamella in chloroplast of upland cotton seedlings; Blue LEDs improved the pigments, photosynthetic rate, leaf thickness, spongy tissue length and stomatal areas; Red LEDs promoted the stem length, leaf area, sucrose, soluble sugar and starch concentrations as well as the number and volume of starch grains in chloroplast. The mixture blue plus red (BR1:8) LEDs light might be propitious and necessary to upland 
cotton seedling growth and can be used as a primary lights for cotton seedling cultivation.

\section{ACKNOWLEDGMENTS}

This work was supported by the key project of natural science in Anhui province department of education (KJ2014A053), and the National 863 Plans Program of China (2013AA103003).

\section{Author's contributions}

C-M.T and Z-G. X design the study. H-M.L did the data analysis and wrote the paper. C-M.T corrected the article.

\section{REFERENCES}

Avercheva, O. V., Y. A. Berkovich, A. N. Erokhin, T. V. Zhigalova, S. I. Pogosyan and S. O. Smolyanina. 2009. Growth and photosynthesis of Chinese cabbage plants grown under light-emitting diode-based light source. Russian J. Plant Physiol. 56: 14-21.

Bondada, B. R. and J. P. Syvertsen. 2005. Concurrent changes in net $\mathrm{CO}_{2}$ assimilation and chloroplast ultrastructure in nitrogen deficient citrus leaves. Environ. Exp. Bot. 54: 41-48.

Britz, S. J. and J. S. Sager. 1990. Photomorphogenesis and photoassimilation in soybean and sorghum grown under broad spectrum or blue-deficient light sources. Plant Physiol. 94: 448-454.

Casal, J. J. 2000. Phytochromes, cryptochromes, phototropin: Photoreceptor interactions in plants. Photochem. Photobiol. 71: 1-11.

Christopher, D. A. and J. E. Mullet. 1994. Separate photosensory pathways co-regulated blue light/ultraviolet-A-activated psbDpsbC transcription and light-induced D2 and CP43 degradation in barley (Hordeum vulgare) chloroplasts. Plant Physiol. 104: 1119-1129.

Deng, L. N. 2007. The Changing of Chloroplast Growth Regulated by Light, PhD Thesis, Beijing Forestry University, Beijing, China.

Dunbar-Co, S., M. J. Sporck and L. Sack 2009. Leaf trait diversification and design in seven rare taxa of the Hawaiian Plantago radiation. Int. J. Plant Sci. 170: 61-75.

Fan, X. X., Z. G. Xu, X. Y. Liu, C. M. Tang, L. W. Wang and X. L. Han. 2013a. Effects of light intensity on the growth and leaf development of young tomato plants grown under a combination of red and blue light. Sci. Hortic. 153: 50-55.

Fan, X. X., J. Zang, Z. G. Xu, S. R. Guo, X. L. Jiao, X. Y. Liu and Y. Gao. 2013b. Effects of different light quality on growth, chlorophyll concentration and chlorophyll biosynthesis precursors of nonheading Chinese cabbage (Brassica campestris L). Acta Physiol. Plant. 35: 2721-2726.

Farquhar, G. D. and T. D. Sharkey. 1982. Stomatal conductance and photosynthesis. Ann. Rev. Plant Physiol. 33: 317-345.

Felker, F. C., D. C. Doehlert and K. Eskins. 1995. Effects of red and blue light on the composition and morphology of maize kernels grown in vitro. Plant Cell Tissue Organ Cult. 42: 147-152.

Geiger, D. R., W. J. Shieh and X. M. Yu. 1995. Photosynthetic carbon metabolism and translocation in wild-type and starch-deficient mutant Nicotinna sylvestris L. Plant Physiol. 107: 507-514.

Gong, W. Z., C. D. Jiang, Y. S. Wu, H. H. Chen, W. Y. Liu and
W. Y. Yang. 2015. Tolerance vs. Avoidance: Two strategies of soybean (Glycine max) seedlings in response to shade in intercropping. Photosynthetica. 53(2): 259-268.

Goins, G. D., N. C. Yorio, M. M. Sanwo and C. S. Brown. 1997. Photomorphogenesis, photosynthesis, and seed yield of wheat plant grown under red light-emitting diodes (LED) with and without supplemental blue lighting. Environ. Exp. Bot. 48: 14071413.

Guan, Z. J., S. B. Zhang, K. Y. Guan, S. Y. Li and H. Hu. 2011. Leaf anatomical structures of Paphiopedilum and Cypripedium and their adaptive significance. J. Plant Res. 124: 289-298.

Guo, S., X. Liu, W. Ai, Y. Tang, J. Zhu, X. Wang, M. Wei, L. Qin and Y. Yang. 2008. Development of an improved ground-based prototype of space plant-growing facility. Adv. Space Res. 41: 736-741.

Hahn, E. J., T. Kozai and K. Y. Paek. 2000. Blue and red lightemitting diodes with or without sucrose and ventilation affects in vitro growth of Rehmannia glutinose plantlets. J. Plant Biol. 43: $247-250$.

Heo, J. W., C. W. Lee, D. Chakrabarty and K. Paek. 2002. Growth responses of marigold and salvia bedding plants as affected by monochromic or mixture radiation provided by a light-emitting diode (LED). Plant Growth Regul. 38: 225-230.

Jao, R. C. and W. Fang. 2004. Effects of frequency and duty ratio on the growth of potato plantlets in vitro using light-emitting diodes. HortScience 39: 375-379.

Kim, H. H., G. D. Goins, R. M. Wheeler and J. C. Sager. 2004. Greenlight supplementation for enhanced lettuce growth under redand blue-light-emitting diodes. HortScience. 39: 1617-1622.

Kim, S. J., E. J. Hahn, J. W. Heo and K. Y. Paek. 2004. Effects of LEDs on net photosynthetic rate, growth and leaf stomata of chrysanthemum plantlets in vitro. Sci. Hortic. 101: 143-151.

Kim, H. H., R. M. Wheeler, J. C. Sager, G. D. Goins and J. H. Norikane. 2006. Evaluation of lettuce growth using supplemental green light with red and blue light-emitting diodes in a controlled environment - A review of research at Kennedy space center. Acta Hortic. 711: 111-119.

Kouakou, T. H., P. Waffo-Téguo, Y. J. Kouadio, J. Valls, T. Richard, A. Decendit and J. M. Merillon. 2007. Phenolic compounds and somatic embryogenesis in cotton (Gossypium hirsutum L.). Plant Cell Tissue Organ Cult. 90: 25-29.

Kowallik, W. 1982. Blue light effects on respiration. Ann. Rev. Plant Physiol. 33: 51-72.

Kurilcik, A., R. Miklusyte-Canova, S. Dapkuniene, S. Zilinskaite, G. Kurilcik, G. Tamulaitis, P. Duchovskis and A. Zukauskas. 2008. In vitro culture of chrysanthemum plantlets using light-emitting diodes. Cent. Eur. J. Biol. 3: 161-167.

Lian, M. L., H. N. Murthy and K. Y. Paek. 2002. Effects of light emitting diodes (LEDs) on the in vitro induction and growth of bulblets of Lilium oriental hybrid 'Pesaro'. Sci. Hortic. 94: 365-370.

Li, H. M., C. M. Tang and Z. G. Xu. 2013. Effect of light emitting diodes on growth and morphogenesis of Rapeseed (Brassica napus L.) plantlets in vitro. Sci. Hortic. 150: 117-124.

Li, H. M., C. M. Tang, Z. G. Xu, X. Y. Liu and X. L. Han. 2012. Effects of different light sources on the growth of non-heading Chinese cabbage (Brassica rapa L.). J. Agric. Sci. 4: 262-273.

Li, H. M., Z. G. Xu and C. M. Tang. 2010. Effect of light-emitting diodes on growth and morphogenesis of upland cotton (Gossypium hirsutum L.) plantlets in vitro. Plant Cell Tissue Organ Cult. 103: $155-163$.

Li, Q. and C. Kubota. 2009. Effects of supplemental light quality on growth and phytochemicals of baby leaf lettuce. Environ. Exp. 
Bot. 67: 59-64.

Lichtenthaler, H. K. and A. R. Wellburn. 1983. Determinations of total carotenoids and chlorophylls $a$ and $b$ of leaf extracts in different solvents. Biochem. Soc. Trans. 603: 91-592.

Liu, X. Y., T. T. Chang, S. R. Guo, Z. G. Xu and J. Li. 2011a. Effect of different light quality of LED on growth and photosynthetic character in cherry tomato seedling. Acta Hortic. 907: 325-330.

Liu, X. Y., S. R. Guo, Z. G. Xu, X. L. Jiao and T. Takafumi. 2011b. Regulation of chloroplast ultrastructure, cross-section anatomy of leaves, and morphology of stomata of cherry tomato by different light irradiations of light-emitting diodes. HortScience. 46: 1-5.

Lund, J. B., T. J. Blom and J. M. Aaslyng. 2007. End-of-day lighting with different red/far-red ratios using light-emitting diodes affects plant growth of chrysanthemum $x$ morifolium ramat 'Coral Charm'. HortScience. 42: 1609-1611.

Martin, A. B., Y. Cuadradoa and H. Guerra. 2000. Differences in the contents of total sugars, reducing sugars, starch and sucrose in embryogenic and nonembrogenic calli from Medicago arborea L. Plant Sci. 154: 143-151.

Moe, R. and R. Heins. 1990. Control of plant morphogenesis and flowering by light quality and temperature. Acta Hortic. 272: $81-89$

Moshe, R. and E. Dalia. 2007. On the effect of light on shoot regeneration in petunia. Plant Cell Tissue Organ Cult. 89: 49-54.

Nhut, D. T., T. Takamura, H. Watanabe, K. Okamoto and M. Tanaka. 2003. Responses of strawberry plantlets cultured in vitro under super bright red and blue light-emitting diodes (LEDs). Plant Cell Tissue Organ Cult. 73: 43-52.

Pan, R. Z., X. J. Wang and N. H. Li. 2008. Plant Physiology, $5^{\text {th }}$ ed. Higher Education Press, Beijing.

Peng, Q. and Q. Zhou. 2009. Influence of lanthanum on chloroplast ultra-structure of soybean leaves under ultraviolet-B stress. J. Rare Earths. 27: 304-307.

Poudel, P. R., I. Kataoka and R. Mochioka. 2008. Effect of red and blue light-emitting diodes on growth and morphogenesis of grapes. Plant Cell Tissue Organ Cult. 92: 147-153.

Saebo, A., T. Krekling and M. Appelgren. 1995. Light quality affects photosynthesis and leaf anatomy of birch plantlets in vitro. Plant Cell Tissue Organ Cult. 41: 177-185.

Sander, W. H., T. Govert, M. Hans, P. Hendrik, V. L. Wim and H. Jeremy. 2010. Blue light dose-responses of leaf photosynthesis, morphology, and chemical composition of Cucumis sativus grown under different combinations of red and blue light. J. Exp. Bot. 61: 3107-3117.

Schuerger, A. C., C. S. Brown and E. C. Stryjewski. 1997. Anatomical features of pepper plants (Capsium annuum L.) grown under red light emitting diodes supplemented with blue or far-red light. Ann. Bot. 79: 273-282.

Senger, H. 1982. The effect of blue light on plants and microorganisms. Photochem. Photobiol. 35: 911-920.

SPSS Inc. 2007. SPSS for Windows. Release 16.0, SPSS Inc., Chicago, IL.

Stutte, G. W. 2009. Light-emitting diodes for manipulating the phytochrome apparatus. HortScience. 44: 231-234.

Stutte, G. W., S. Edney and T. Skerritt. 2009. Photoregulation of bioprotectant content of red leaf lettuce with light-emitting diodes. HortScience. 44: 79-82.

Takahashi, K., K. Fujino, Y. Kikuta and Y. Koda. 1995. Involvement of the accumulation of sucrose and the synthesis of cell wall polysaccharides in the expansion of potato cells in response to Jasmonic acid. Plant Sci. 111: 11-18.

Tanaka, M., T. Takamura, H. Watanabe, M. Endo, T. Yanagi and K. Okamoto. 1998. In vitro growth of Cymbidium plantlets cultured under super bright red and blue light emitting diodes (LEDs). J. Hortic. Sci. Biotechnol. 73: 39-44.

Whitelam, G. and K. Halliday. 2007. Light and Plant Development, Blackwell Publishing, Oxford, UK

Wyka, T., P. Robakowski and R. Zytkowiak. 2008. Leaf age as a factor in anatomical and physiological acclimative responses of Taxus baccata L. Needles to contrasting irradiance environments. Photosynth. Res. 95: 87-99.

Yorio, N. C., G. D. Goins, H. R. Kagie, R. M. Wheeler and J. C. Sager. 2001. Improving spinach, radish, and lettuce growth under red light-emitting diodes (LEDs) with blue light supplementation. HortScience. 36: 380-383.

Zeng, B., X. M. Xu, S. X. Zhou, C. S. Zhu and C. M. Tang. 2012. Effects of temperature and light on photosynthetic heterosis of an upland cotton hybrid cultivar. Crop Sci. 52: 282-291.

Zhang, H., Z. G. Xu, J. Cui, A. S. Gu and Y. S. Guo. 2010. Effects of light quality on the growth and chloroplast ultra-structure of tomato and lettuce seedlings. Chin. J. Appl. Ecol. 21: 956-965.

Zhang, H. S., D. M. Li, Q. P. Tan, H. Y. Gao and D. S. Gao. 2015. Photosynthetic activities, C3, and C4, indicative enzymes and the role of photoperiod in dormancy induction in 'Chunjie' peach. Photosynthetica. 53: 1-10. 